Article

\title{
Extraction and Fractionation of Bioactives from Dipsacus fullonum L. Leaves and Evaluation of Their Anti-Borrelia Activity
}

\author{
Piret Saar-Reismaa $^{1}{ }^{\mathbb{D}}$, Olga Bragina ${ }^{1,2}$, Maria Kuhtinskaja ${ }^{1}$, Indrek Reile ${ }^{3} \mathbb{D}$, Pille-Riin Laanet ${ }^{1} \mathbb{D}$, Maria Kulp $^{1}$ \\ and Merike Vaher $1, *$ (D) \\ 1 Department of Chemistry and Biotechnology, School of Science, Tallinn University of Technology, \\ 12618 Tallinn, Estonia; piret.saar1@taltech.ee (P.S.-R.); olga.bragina@taltech.ee (O.B.); \\ maria.kuhtinskaja@taltech.ee (M.K.); pille-riin.laanet@taltech.ee (P.-R.L.); maria.kulp@taltech.ee (M.K.) \\ 2 National Institute for Health Development, 11619 Tallinn, Estonia \\ 3 National Institute of Chemical Physics and Biophysics, 12618 Tallinn, Estonia; indrek.reile@kbfi.ee \\ * Correspondence: merike.vaher@taltech.ee; Tel.: +37-2620-4359
}

check for updates

Citation: Saar-Reismaa, P.; Bragina, O.; Kuhtinskaja, M.; Reile, I.; Laanet, P.-R.; Kulp, M.; Vaher, M. Extraction and Fractionation of Bioactives from Dipsacus fullonum L. Leaves and Evaluation of Their Anti-Borrelia Activity. Pharmaceuticals 2022, 15, 87. https://doi.org/10.3390/ ph15010087

Academic Editors: Eduarda M. P. Silva and Diana Cláudia Pinto

Received: 8 December 2021 Accepted: 11 January 2022 Published: 12 January 2022

Publisher's Note: MDPI stays neutral with regard to jurisdictional claims in published maps and institutional affiliations.

Copyright: () 2022 by the authors Licensee MDPI, Basel, Switzerland. This article is an open access article distributed under the terms and conditions of the Creative Commons Attribution (CC BY) license (https:// creativecommons.org/licenses/by/ $4.0 /)$.

\begin{abstract}
Lyme disease (LD) is a tick-borne bacterial disease that is caused by Borrelia burgdorferi. Although acute LD is treated with antibiotics, it can develop into relapsing chronic form caused by latent forms of B. burgdorferi. This leads to the search for phytochemicals against resistant LD. Therefore, this study aimed to evaluate the activity of Dipsacus fullonum L. leaves extract (DE) and its fractions against stationary phase B. burgdorferi in vitro. DE showed high activity against stationary phase B. burgdorferi (residual viability $19.8 \pm 4.7 \%$ ); however, it exhibited a noticeable cytotoxicity on NIH cells (viability $20.2 \pm 5.2 \%$ ). The iridoid-glycoside fraction showed a remarkable anti-Borrelia effect and reduced cytotoxicity. The iridoid-glycoside fraction was, therefore, further purified and showed to contain two main bioactives-sylvestrosides III and IV, that showed a considerable antiBorrelia activity being the least toxic to murine fibroblast NIH/3T3 cells. Moreover, the concentration of sylvestrosides was about $15 \%$ of DE, endorsing the feasibility of purification of the compounds from D. fullonum L. leaves.
\end{abstract}

Keywords: Dipsacus fullonum L.; Borrelia burgdorferi; antibacterial activity; bis-iridoids; sylvestrosides; cytotoxicity

\section{Introduction}

Borreliosis, also known as Lyme disease (LD), is a well-known multisystemic bacterial disease. It is caused by Borrelia burgdorferi (B. burgdorferi), a spirochete, that is transmitted to humans from ticks. Lyme disease has various symptoms from localized skin deformities and joint pains, and even affects the heart and other muscles [1,2]. The most severe form is neuroborreliosis, which may lead to a variety of neurological manifestations from painful meningoradiculitis, ataxia, confusion and even ischemic stroke [3]. Modern medicine uses antibiotics to cure acute LD cases, where B. burgdorferi is mainly in an active spirochete form. When hostile conditions are introduced, for example, the widely used antibiotics such as doxycycline, amoxicillin and ceftriaxone [4,5], these bacteria can adopt different latent forms such as rounded bodies and aggregates (biofilm-like structures) that are considerably less affected by the treatment of one or even a mixture of antibiotics [5,6]. This ineffective treatment may lead to LD becoming persistent and/or resurfacing after being silent for a long time, named as a post-treatment Lyme disease syndrome that presents with chronic, persistent fatigue, musculoskeletal pain and neurocognitive difficulties for over 6 months after the primary treatment [7].

This leads to the search for novel substances that could be used as remedies. One possible source of new bacteriostatic phytochemicals is of natural origin-plants. The use 
of medicinal plants is widely known in case of various bacterial diseases. There are several reports demonstrating the ability of various bioactive plants to act as antibacterial agents. For example, grape (Vitis vinifera) seed extract [8], sugar leaf (Stevia rebaudiana) [9] and cat's claw (Uncaria tomentosa) [6] have shown potential activity against acute Borrelia spirochetes and the nongrowing stationary phase. This is further supported by the use of treatments where phytochemicals are used in combination with antibiotics [10] or micronutrients such as vitamin D [11], enabling lower LD $_{50}$ (median lethal dose) and MIC (minimum inhibitory concentration) concentrations against latent rounded forms of B. burgdorferi. This demonstrates a wide future potential of novel bioactives as both individual and synergic compounds for possible anti-Borrelia treatments [10,11].

A promising plant source is the genus Dipsacus. The root is known as "Xu duan" in Chinese medicine and is famous for its anti-cancer and anti-inflammatory properties and is even used for treating Alzheimer [12]. Dipsacus has mostly been applied as an arthritis remedy [13]. One of the most studied species is D. asper, with the focus on the root or the seeds of the plant [12]. Dipsacus fullonum L., also known as wild teasel (shown in Figure 1) and its roots have also been characterized as a potential source of anti-Borrelia bioactives [14]. Previously, all the known anti-Borrelia research focused on the radix-the root of the plant with minimal activity against Lyme disease [15]. It has also been demonstrated that the composition of the leaves significantly differs from that of the root [16], demonstrating good antioxidant and antimicrobial activities [16,17]. Moreover, our research group's investigations have established the in vivo effectiveness of teasel leaves extracts against several cancer strains [18].

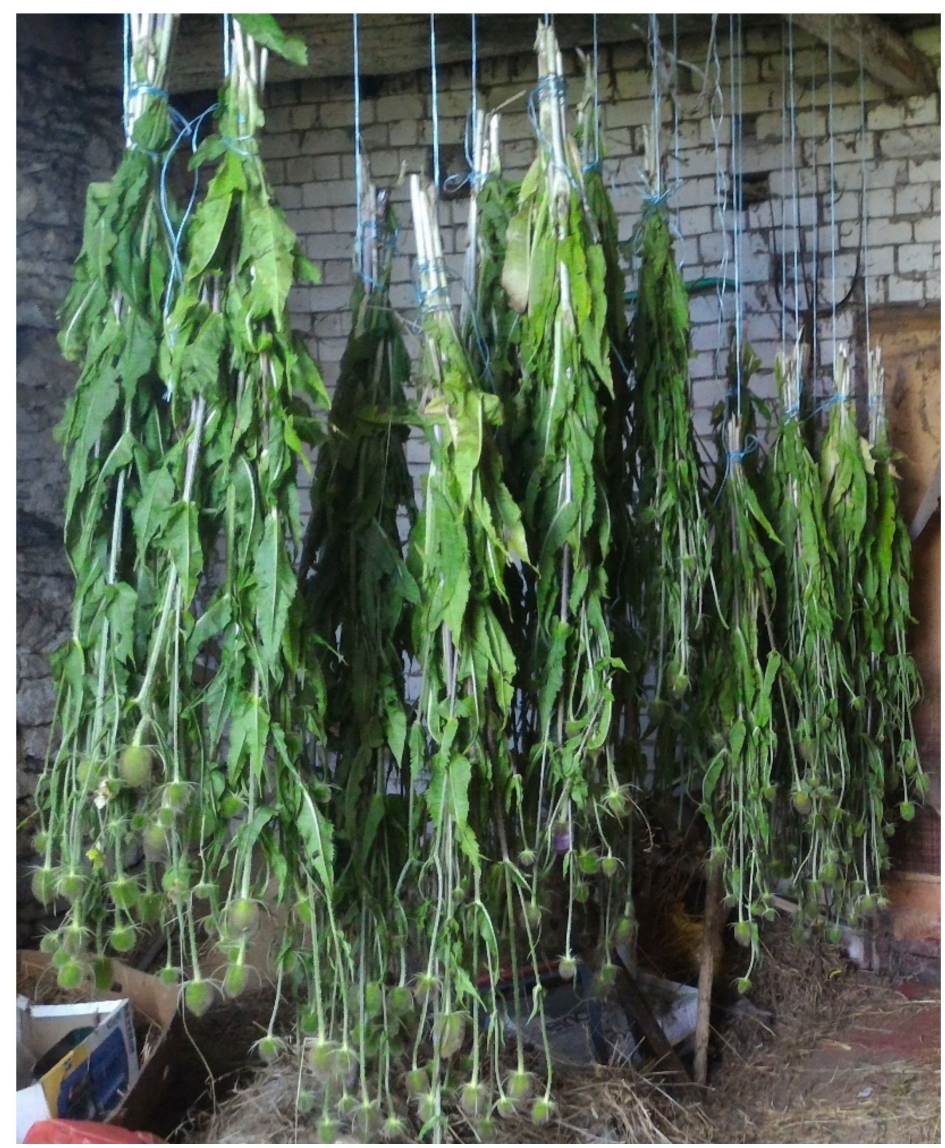

Figure 1. Dipsacus fullonum L. harvested from Saaremaa, Estonia, 2017.

The current study aimed to continue our research group's earlier investigations on D. fullonum L. leaves $[18,19]$ by elucidating, fractionating, identifying and quantifying the content of D. fullonum L. bioactives (iridoids and polyphenolics) to evaluate their 
anti-Borrelia activity against stationary phase Borrelia burgdorferi. Additionally, the composition of the more promising fractions was identified and quantified together with their antioxidative capacity, anti-Borrelia activity and cytotoxicity evaluated.

\section{Results and Discussion}

Recently, the extract from $D$. fullonum L. leaves was evaluated; however, the analysis was limited to the antioxidant, anticholinesterase and antidiabetic effects only [16]. To evaluate the leaf extract for anti-Borrelia effects, the first step was the analysis of DE by HPLC-DAD-MS to obtain a reliable chromatographic separation for the determination and quantification of the main constituents. A total of 20 major components were identified and quantified in the extract. A representative chromatogram of DE is shown in Figure 2. DE was diluted 20 times for evaluation against stationary phase $B$. burgdorferi with a gross concentration of $305.5 \pm 24.5 \mathrm{mg} / \mathrm{L}$ of the chosen 20 compounds of interest. The quantification was achieved as described in the previous section according to the DAD signal and chlorogenic acid, loganin, saponarin, isoorientin or isovitexin calibrations, accordingly.

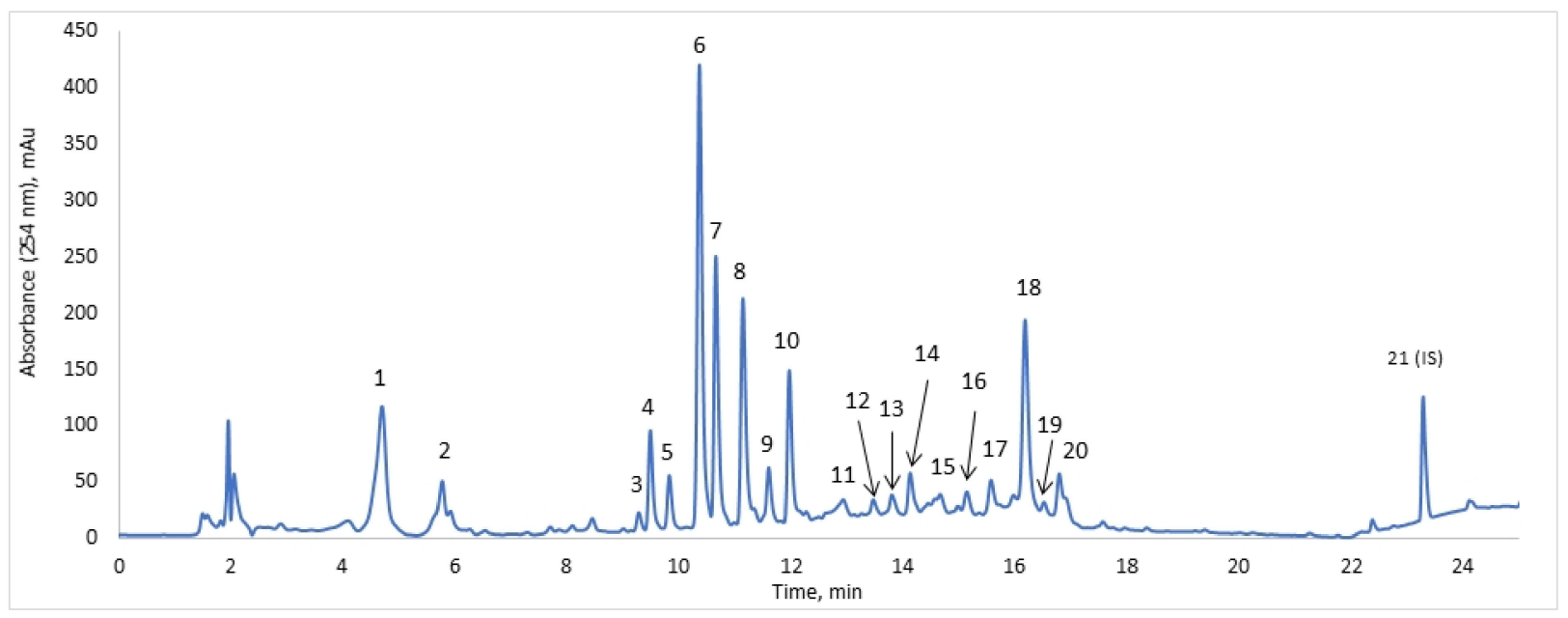

Figure 2. Chromatogram of DE, with selected peaks for quantification. The results of identification are presented in Table 1. Peak 21-internal standard, bicalutamide, $40.0 \mathrm{mg} / \mathrm{L}$.

The identification was performed using available reference standards and literature comparison to the MS/MS fragmentation pattern and UV spectra. Two main classes of substances were identified: polyphenols and iridoids. The two major polyphenols were saponarin (apigenin-6-C-glucoside-7-O-glucoside, peak 6) and chlorogenic acid (peak 1), which were the most abundantly found species in previous studies of D. fullonum L. leaves [16] and D. sativus leaves [17]. The main iridoids were sylvestrosides III and IV (peak 18), and loganic acid and loganin (peaks 2 and 4, respectively).

Quantitatively, the highest amounts of compounds were as follows: saponarin (17.2\%), chlorogenic acid (17.1\%), the mixture of sylvestrosides III and IV (15.2\%) at a ratio of 0.9:1.0, dichlorogenic acid isomer (14.2\%), isoorientin (5.8\%), loganin (4.9\%) and isovitexin (4.2\%), correspondingly. Although orientin [16] and isoorientin [17] have both been reported in literature, the $\mathrm{MS}^{2}$ fragmentation pattern and comparison to the chromatographic parameters of the orientin standard clearly demonstrated peak 7 to be isoorientin instead of orientin. The concentrations of the tested DE on the stationary phase of Borrelia with identification parameters are given in Table 1. 
Table 1. Identification and concentrations of DE compounds.

\begin{tabular}{|c|c|c|c|c|c|c|}
\hline Peak & Compound & $\mathrm{T}_{\text {ret}}, \mathrm{Min}$ & $\lambda \max , \mathrm{nm}$ & MS, $m / z$ & MS/MS, $m / z$ & Conc., mg/L \\
\hline 1 & Chlorogenic acid & 4.7 & $245 ; 325$ & 353 & 191 & $47.8 \pm 2.7$ \\
\hline 2 & Loganic acid & 5.8 & 230 & 375 & $213 ; 169$ & $14.6 \pm 2.1$ \\
\hline 3 & Luteolin derivative & 9.3 & $270 ; 350$ & 609 & $447 ; 325$ & $0.8 \pm 0.3$ \\
\hline 4 & Loganin & 9.5 & 238 & 389 & $227 ; 209$ & $13.6 \pm 0.7$ \\
\hline 5 & Loganic acid ethyl ester & 9.8 & 245 & 403 & $395 ; 357$ & $6.0 \pm 0.5$ \\
\hline 6 & Saponarin & 10.4 & $270 ; 335$ & 593 & $311 ; 431 ; 473$ & $48.1 \pm 6.1$ \\
\hline 7 & Isoorientin & 10.7 & 347 & 447 & $557 ; 327 ; 429$ & $16.3 \pm 2.1$ \\
\hline 8 & Dichlorogenic acid isomer & 11.1 & 325 & 515 & $353 ; 191$ & $39.7 \pm 1.9$ \\
\hline 9 & Dichlorogenic acid isomer & 11.6 & 325 & 515 & $353 ; 173 ; 203$ & $3.6 \pm 3.2$ \\
\hline 10 & Isovitexin & 12.0 & $268 ; 340$ & 431 & $311 ; 341 ; 413$ & $11.7 \pm 0.5$ \\
\hline 11 & bis-Iridoid glycoside & 12.9 & 238 & 541 & - & $4.4 \pm 0.8$ \\
\hline 12 & bis-Iridoid glycoside & 13.5 & 240 & 585 & 373 & $0.8 \pm 0.3$ \\
\hline 13 & bis-Iridoid glycoside & 13.8 & 240 & 583 & $513 ; 459$ & $1.0 \pm 0.6$ \\
\hline 14 & bis-Iridoid glycoside & 14.1 & 240 & 585 & 373 & $5.0 \pm 0.7$ \\
\hline 15 & bis-Iridoid glycoside & 14.7 & 240 & 585 & 373 & $4.8 \pm 0.9$ \\
\hline 16 & bis-Iridoid glycoside & 15.1 & 240 & 585 & 373 & $2.9 \pm 0.4$ \\
\hline 17 & bis-Iridoid glycoside & 15.6 & 240 & 583 & 373 & $4.9 \pm 1.6$ \\
\hline 18 & Sylvestrosides III and IV & 16.2 & 240 & 583 & 373 & $42.5 \pm 4.7$ \\
\hline 19 & bis-Iridoid glycoside & 16.5 & 240 & 583 & 373 & $0.9 \pm 0.2$ \\
\hline 20 & bis-Iridoid glycoside & 16.8 & 240 & 583 & 373 & $10.5 \pm 0.1$ \\
\hline 21 & Bicalutamide (IS) & 23.3 & $215 ; 270$ & 429 & $255 ; 183$ & 500 \\
\hline
\end{tabular}

Using characteristic peaks from each NP fraction, dilutions were made to correlate gross concentrations with that of DE. All the diluted NP fractions were then used for primary screening against stationary phase Borrelia burgdorferi in vivo to detect active fractions for further analysis. The results from the primary evaluation are given in Table 2, where the fraction was considered active if it revealed a significant effect on the residual viability of the stationary phase B. burgdorferi.

Table 2. Preliminary screening for activity against stationary phase B. burgdorferi.

\begin{tabular}{ccc}
\hline NP Number & Main Constituents & Activity \\
\hline NP1 & Chlorophylls & - \\
NP2 & bis-Iridoids $(m / z 585,583)$ & + \\
NP3 & Iridoids-loganin, loganic acid ethyl ester & - \\
NP4 & Loganin derivatives & - \\
NP5 & Loganic acid & + \\
NP6 & Isovitexin, saponarin, isoorientin & + \\
NP7 & Saponarin, isoorientin, 2 chlorogenic acid derivatives & + \\
NP8 & Saponarin, isoorientin, chlorogenic acid & + \\
\hline
\end{tabular}

The first normal phase fraction, NP1, did not contain any of the raw extract compounds at $254 \mathrm{~nm}$, which could be explained by the fact that NP1 contained mainly chlorophylls that were not soluble in $70 \% \mathrm{EtOH}$ and did not absorb. This was further correlated by the TLC results, where the first fractions had a characteristic emission at $312 \mathrm{~nm}$ corresponding to chlorophylls [20]. No activity was observed in fraction NP3, which included loganin and loganic acid ethyl ester, and was first purified from $D$. asper roots and showed moderate neuroprotective effects [21]. Loganin has been frequently identified in various Dipsacaceae plants in roots, seeds and leaves [12]. Similarly, fraction NP4 contained mainly loganin derivatives, which did not show any specific activity against the tested cultures either. The lack of anti-Borrelia activity could be explained by the low concentration of the compounds.

However, several of the fractions demonstrated in vitro activity against stationary phase $B$. burgdorferi in the concentration ranges similar to those of raw extracts. The main constituents of NP2 were assigned to iridoid glycosides, having $m / z$ values of 583 and 585 . 
A similar fraction produced and tested previously by our group has shown activity against the selective cytotoxic effect on human breast cancer cell lines MCF7 and MDB-MD-231 [18]. Fraction NP5 contained mainly loganic acid, which also exhibited anti-Borrelia activity, similarly to iridoids from fraction NP2. Moreover, loganic acid has been shown to have anti-infectivity activity [22] and thus fractions NP2 and NP5 were further analyzed.

Fractions NP6 to NP8 contained various phenolic compounds, mainly glycosides of apigenin and luteolin, as well as chlorogenic acid and its derivates. Although flavonoids such as apigenin and luteolin have shown to be cytotoxic, their glycosides were much less so [23]. Previously, the phenolic extracts from D. sativus containing saponarin, isoorientin and isovitexin have been proven to reveal antioxidant activities [17], and moreover, saponarin has been recently shown to possess anti-inflammatory and anti-allergic effects [24]. The other main constituents were chlorogenic acid (NP8) and dichlorogenic acid isomers (NP7). As chlorogenic acid has shown potential anti-cancer and other healthbeneficial effects, but in much higher concentrations ( $2 \mathrm{mM}$ or above), it may also have cytotoxic effects [25], fraction NP8 was discarded from additional experiments and only NP7 was used as it contained similar substances. To further evaluate the possible synergistic effects of individual substances, isovitexin and luteolin were used as standards. Isovitexin showed cytotoxicity at active concentrations or even three times diluted $(100 \mathrm{mg} / \mathrm{L})(\mathrm{data}$ not shown); thus fraction NP6 was also excluded from further specific analysis.

As a result, the 70\% EtOH (v/v \%) DE, NP2, NP5 and NP7 remained as possible candidates for additional in-depth analysis with stationary phase B. burgdorferi. To further evaluate the possible synergistic effects of the fractions under analysis a designed mixture (DM) composed of NP2 and NP7 fractions at a ratio of 1:3 was made to replicate the iridoid and polyphenol fractions without additional substances. All the viability results were compared to those of a mixture of the most common antibiotics for the early stage Lyme borreliosis doxycycline and cefuroxime [2]. The residual viability of stationary phase B. burgdorferi of samples is given in Table 3 .

Table 3. Effect of DE and its fractions on the seven-day old stationary phase B. burgdorferi.

\begin{tabular}{ccc}
\hline Sample & Gross Conc., $\mathbf{~ m g / L}$ & Residual Viability, \% \\
\hline DE & $305.5 \pm 24.5$ & $19.8 \pm 4.7$ \\
NP2 & $295.4 \pm 12.1$ & $54.3 \pm 10.4$ \\
NP5 & $332.8 \pm 34.7$ & $29.8 \pm 7.8$ \\
NP7 & $340.2 \pm 14.5$ & $23.4 \pm 15.8$ \\
DM & $308.6 \pm 20.2$ & $40.2 \pm 9.1$ \\
NP2-RP & $300.2 \pm 8.9$ & $64.5 \pm 14.9$ \\
Dox., Cefo., Dap. * & $22.2 ; 33.4 ; 80.1$ & $24.9 \pm 7.4$
\end{tabular}

The raw DE has the highest anti-Borrelia activity, $19.8 \pm 4.7 \%$, followed by NP5 (loganic acid) and NP7 (saponarin, isoorientin and dichlorogenic acid derivatives), all below 30\%. Previously, only the lipophilic extract of D. fullonum L. has shown anti-borrelia effects [14], but the results of this study show that a hydrophilic extract contains several anti-Borrelia compounds. The iridoid fraction NP2 and the DM mixture demonstrated moderate effects against the stationary phase bacteria. A recent study reported that the combination of doxycycline, cefoperazone and daptomycin successfully eliminated both spirochetes and persisters [26]. Our data from the present study also confirmed the effectiveness of this triple-antibiotic combination on B. burgdorferi by significantly reducing the viability of the stationary phase culture, by about $76 \%$.

As polyphenols have been previously extensively researched and have shown significant anti-oxidative and anti-cancer effects [27] as well as relatively high cytotoxicity [28], the focus was on fraction NP2, which contained iridoid glycosides. As the HPLC-DAD-MS analysis demonstrated that this fraction contained several bis-iridoids as well as sylvestrosides III and IV, further purification was performed by RPFC as described in the Methods 
and Materials section. The NP2-RP fraction obtained was reanalyzed by HPLC-DAD-MS and was further confirmed by NMR analysis to contain sylvestrosides III and IV at a ratio of 0.9:1:0 with slightly more sylvestroside IV, as described in Section 3.4. Previously, both sylvestroside III and IV have been found in Dipsacus laciniatus, where sylvestroside IV was in abundance compared to sylvestroside III, 5.2 and $0.8 \mathrm{mg}$ in $100 \mathrm{~g}$ fresh plant, respectively [29]. In D. fullonum L., the ratio has also been with mostly sylvestroside IV (153 mg/100 g fresh material) to sylvestroside III (100 mg/100 g fresh material) [30]. The anti-inflammatory activity of sylvestrosides I, II, III and IV have been previously demonstrated by Chen et al. [31] contributing to the potential for investigation as anti-Borrelia compounds. Therefore, NP2-RP was subjected to in vitro testing against stationary phase $B$. burgdorferi with positive results as the fraction provided a residual viability of $64.5 \pm 14.0 \%$. Moreover, sylvestroside III and IV were in abundance in the overall extract at $15.2 \%$ of gross concentration, which is similar to previously published amount of $10 \%$ of sylvestroside III by Oszmiański et al. [16]. Although they identify only sylvestroside III, it is assumed that the combination of sylvestroside III and IV is meant as the use of HPLC-DAD-MS with water-ACN as eluents does not provide separation of III and IV. Therefore, the bioactives from the iridoid fraction NP2 were sylvestrosides III and IV and could be further tested for additional anti-Borrelia activity as separate bioactives or in combination with other phytochemicals/antibiotics.

The evaluation of DE and its fractions also included the determination of cytotoxicity against normal mammalian cells to ensure the applicability of the compounds in the used concentrations. The cytotoxicity of DE and its fractions was determined using the WST1 assay, where NIH 3T3 cells were treated with DE and its fractions and the viability parameters were registered after $48 \mathrm{~h}$ and are presented in Figure 3. The results obtained clearly showed the need for fractionation and purification of the raw extract, which had only a $20.2 \pm 5.2 \%$ cell viability, against the $71.1 \pm 6.1 \%$ of the NP2-RP fraction. Based on the WST-1 assay results, the cytotoxicity arose from polyphenols as the NP7 fraction had a viability of $54.7 \pm 9.2 \%$. These results correlate with those of our previous studies on iridoid fractions having a $63.3 \pm 13.7 \%$ viability [18]. The detailed results of the statistical comparison test are given in Supplementary Materials File S1.

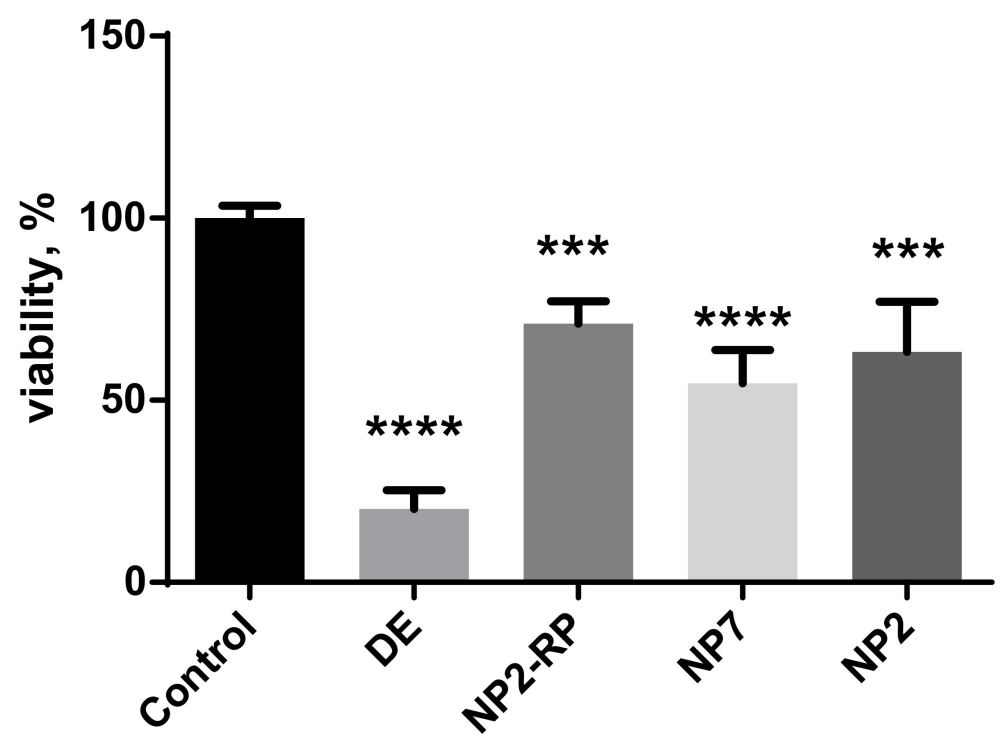

Figure 3. Cytotoxic effect of DE and its fractions on NIH 3T3 cells assessed by WST1 assay after $48 \mathrm{~h}$. The experiments were run triplicate. The graphs represent as mean \pm SD. Cells treated with $60 \%$ EtOH were normalized to $100 \%$ as control; $p<0.001$ as $* * *, p<0.0001$ as $* * * *$.

Moreover, the antioxidant activity of the active fractions was evaluated by the oxygen radical absorbance capacity. The raw extract demonstrated an activity of $10.8 \pm 0.8 \mathrm{mmol} \mathrm{TE} /$ $100 \mathrm{~mL}$, being similar to the previously obtained results for D. fullonum L. leaves extract [16]. 
NP7 exhibited the highest activity, $12.5 \pm 0.1 \mathrm{mmol} \mathrm{TE} / 100 \mathrm{~mL}$, which corresponds to that of the polyphenolic fraction, including flavonoids saponarin and isoorientin. These flavonoids are well known as antioxidants and free-radical scavengers [17]. The iridoidglycoside fractions NP2 and NP2-RP tested only showed an activity of $0.78 \pm 0.06$ and $0.27 \pm 0.02 \mathrm{mmol} \mathrm{TE} / 100 \mathrm{~mL}$, respectively. The results correlate with the data of previous studies on the ORAC of D. fullonum L. leaves extract by Oszmianski et al. (2020) [16] and further confirms their proposed activity, originating from polyphenolics rather than iridoids.

\section{Materials and Methods}

\subsection{Plant Material}

The Dipsacus fullonum L. was collected from Saaremaa, Estonia, in the summer of 2017 (pictured in Figure 1). The identification of the plant was performed by comparison with an authentic specimen Dipsacus fullonum L., and a voucher specimen was deposited in the Herbarium of the Institute of Agricultural and Environmental Sciences of the Estonian University of Life Sciences, herbarium specimens TAA0153271-TAA0153274. The leaves were separated manually, washed with Milli-Q water and dried in a well-ventilated room at room temperature $\left(25-30{ }^{\circ} \mathrm{C}\right)$ for four weeks. The dried leaves were powdered in a mechanical Fritsch Universal Cutting Mill pulverisette 19 grinder (Weimar, Germany) and mixed together. The mixture was stored in an air-tight container protected from sunlight in the laboratory at $23^{\circ} \mathrm{C}$.

\subsection{Preparation of D. fullonum Extract}

The extraction procedure was modified from our previous study [19]. Briefly, $50.0 \mathrm{~g}$ of the pulverized leaves of D. fullonum L. were weighed into a flask and $250 \mathrm{~mL}$ of $70 \%(v / v \%)$ ethanol (EtOH) was added. The extract was shaken on an Orbital Shaker DOS-20M (Elmi, Newbury Park, CA, USA) for $25 \mathrm{~min}$ at $250 \mathrm{rpm}$ and ultrasonicated at $40{ }^{\circ} \mathrm{C}$ for $30 \mathrm{~min}$. The extract was decanted into a volume cylinder. Another $250 \mathrm{~mL}$ of $70 \% \mathrm{EtOH}$ was added and shaken for $30 \mathrm{~min}$ and the extracts were combined. The raw D. fullonum L. leaves extract (DE) was then filtered through a blue Whatman filter paper (Buckinghamshire, UK) and used for further extraction or analysis.

\subsection{Isolation of D. fullonum L. Constituents}

The D. fullonum L. leaves extract was concentrated 20 times by volume, using a rotary Laborota 4000, Heidolph (Schwabach, Germany) evaporator. Eight milliliters of the concentrated extract was added to $7 \mathrm{~g}$ of silica gel. The extract was rotated dry on a rotary evaporator and subjected to normal-phase silica gel column $(40-100 \mu \mathrm{m})(40 \mathrm{~mm}$, $140 \mathrm{~mm})\left(60 \mathrm{~g}, \mathrm{CHCl}_{3} \rightarrow \mathrm{CHCl}_{3}: \mathrm{MeOH}\right.$ 9:1 $\rightarrow \mathrm{CHCl}_{3}: \mathrm{MeOH}$ 8:2 $\rightarrow \mathrm{CHCl}_{3}: \mathrm{MeOH}$ 7:3 $\rightarrow \mathrm{CHCl}_{3}: \mathrm{MeOH}$ 6:4 $\rightarrow \mathrm{CHCl}_{3}: \mathrm{MeOH}$ 5:5 $\rightarrow \mathrm{CHCl}_{3}: \mathrm{MeOH}$ 4:6 $\rightarrow \mathrm{CHCl}_{3}: \mathrm{MeOH}$ 3:7 $\rightarrow$ $\mathrm{CHCl}_{3}: \mathrm{MeOH}$ 2:8 $\rightarrow \mathrm{CHCl}_{3}: \mathrm{MeOH}$ 1:9 $\left.\rightarrow \mathrm{MeOH}\right)$ to give 30 fractions per column. Altogether, 16 columns were made. The collected normal-phase fractions were analyzed using thin-layer chromatography (TLC) to combine similar fractions. Three microliters of each fraction was manually applied to $5 \times 10 \mathrm{~cm}$ TLC silica gel 60 F254 $(0.20 \mathrm{~mm})$ sheets (Macherey-Nagel, Düren, Germany). The sheets were placed in a saturated development chamber with a reagent mixture of n-butanol:Milli-Q water:EtOH 4:1:1. The plates were air-dried and subjected to analysis at 254 and $312 \mathrm{~nm}$. Accordingly, the first 30 fractions were combined into 8 normal-phase fractions (NP), NP1 to NP8 corresponding to the TLC bands. NP1 to NP8 were evaporated dry and resolubilized in 70\% EtOH. All eight NP fractions were then analyzed using HPLC-DAD-MS.

Fraction NP2 was further subjected to reversed-phase flash chromatography (RPFC) for further purification. The purification was achieved by elution through the Biotage Sfär C18 column (12 g, $30 \mu \mathrm{m}, 100 \AA$, Uppsala, Sweden). Elution in RPFC was carried out with a mobile phase of $20 \% \mathrm{ACN} / 80 \%$ Milli-Q water (isocratic elution) with a flow rate of $30 \mathrm{~mL} / \mathrm{min}$. The elutes were scanned continuously at 210 and $238 \mathrm{~nm}$ throughout the experiment. The fractions were automatically collected into the test tubes. Each frac- 
tion (without any additional evaporation) was subjected to the HPLC-DAD-MS analysis. The fractions with a high iridoid content and maximally free of contaminants were combined and evaporated to dryness giving NP2-RP as yellow-brownish crystals, which were analyzed by HPLC-DAD-MS and NMR spectroscopy.

\subsection{NMR Analysis}

Nuclear magnetic resonance analysis was carried out on a $500 \mathrm{MHz}$ Agilent DD2 spectrometer equipped with a $5 \mathrm{~mm}$ ID probe. Fifty milligrams of the product fraction NP2-RP was dissolved in $600 \mu \mathrm{L}$ of acetone- $\mathrm{d}_{6}$ and subjected to analysis at $25^{\circ} \mathrm{C}$ sample temperature. Spectra were referenced according to the residual solvent peak at $2.05 \mathrm{ppm}$. Identification of products was achieved by conducting ${ }^{1} \mathrm{H},{ }^{13} \mathrm{C}$, COSY, TOCSY, HSQC, HMBC and $\mathrm{H} 2 \mathrm{BC}$ analysis of the mixture and comparing spectra with literature data $[29,30,32]$. Several ${ }^{1} \mathrm{H}$ signals of the mixture components were overlapping in 1D spectra and were resolved only by $2 \mathrm{D}$ methods, making the identification of multiplet structures complicated. Sylvestroside III and sylvestroside IV were identified as the major components of NP2-RP with a molar ratio of 0.9:1.0. The ratio was established by comparing HSQC signal integrals from sylvestroside III and sylvestroside IV iridoid unit's bridging 5- and 9-positions. Assuming the relaxation and $\mathrm{C}-\mathrm{H}$ coupling parameters of both positions in either compound are likely similar, HSQC integrals allow establishing the relative abundance of both. Integral comparisons for 5- and 9-positions in either compound gave the same result. Full NMR spectra are shown in Supplementary Materials File S2. The compounds were characterized as:

Sylvestroside III: ${ }^{1} \mathrm{H}-\mathrm{NMR}\left(500 \mathrm{MHz}\right.$, acetone- $\left.\mathrm{d}_{6}\right) \delta=9.71$ (broad, $\left.1 \mathrm{H}\right), 7.59$ (broad, $1 \mathrm{H}), 7.55($ broad, $1 \mathrm{H}), 5.62(\mathrm{~m}, 1 \mathrm{H}), 5.47(\mathrm{~m}, 1 \mathrm{H}), 5.26(\mathrm{~m}, 1 \mathrm{H}), 5.21(\mathrm{~m}, 1 \mathrm{H}), 5.00(\mathrm{~d}, \mathrm{~J}=6.2$, $1 \mathrm{H}), 4.72(\mathrm{~m}, 1 \mathrm{H}), 3.87(\mathrm{~d}, \mathrm{~J}=12.1 \mathrm{~Hz}, 1 \mathrm{H}), 3.67(\mathrm{~d}, 9.5 \mathrm{~Hz}, 1 \mathrm{H}), 3.65(\mathrm{~s}, 3 \mathrm{H}), 3.44(\mathrm{~m}, 2 \mathrm{H})$, $3.43(\mathrm{~m}, 1 \mathrm{H}), 3.38(\mathrm{~m}, 1 \mathrm{H}), 3.25(\mathrm{~m}, 1 \mathrm{H}), 3.06(\mathrm{~m}, 1 \mathrm{H}), 2.78(\mathrm{~m}, 1 \mathrm{H}), 2.74(\mathrm{~m}, 1 \mathrm{H}), 2.48(\mathrm{~m}$, 1H), $2.29(\mathrm{~m}, 1 \mathrm{H}), 2.13(\mathrm{~m}, 1 \mathrm{H}), 1.92(\mathrm{~m}, 1 \mathrm{H}), 1.65(\mathrm{~m}, 1 \mathrm{H}), 1.06(\mathrm{~d}, \mathrm{~J}=7.1 \mathrm{~Hz}, 3 \mathrm{H}) ;{ }^{13} \mathrm{C}-\mathrm{NMR}$ $\left(125 \mathrm{MHz}\right.$, acetone- $\left.\mathrm{d}_{6}\right) \delta=206.4,168.1,166.8,153.3,153.0,134.8,120.2,111.5,109.7,99.7$, 96.7, 96.5, 77.9, 77.7, 77.2, 74.3, 71.3, 62.7, 51.3, 48.0, 44.8, 44.7, 41.2, 40.3, 33.2, 27.1, 14.3.

Sylvestroside IV: ${ }^{1} \mathrm{H}-\mathrm{NMR}\left(500 \mathrm{MHz}\right.$, acetone- $\left.\mathrm{d}_{6}\right) \delta=9.7$ (broad s, $\left.1 \mathrm{H}\right), 7.53$ (broad, $1 \mathrm{H}), 5.6(\mathrm{~m}, 1 \mathrm{H}), 5.48(\mathrm{~m}, 1 \mathrm{H}), 5.23(\mathrm{~m}, 3 \mathrm{H}), 4.72(\mathrm{~m}, 1 \mathrm{H}), 4.42(\mathrm{dd}, \mathrm{J}=11.6 \mathrm{~Hz}, 5.6 \mathrm{~Hz} ; 1 \mathrm{H})$, $4.22(\mathrm{~m}, 1 \mathrm{H}), 3.87(\mathrm{~d}, \mathrm{~J}=12.1 \mathrm{~Hz}, 1 \mathrm{H}), 3.73(\mathrm{~s}, 3 \mathrm{H}), 3.69(\mathrm{broad}, 1 \mathrm{H}), 3.67(\mathrm{~d}, 9.5 \mathrm{~Hz}, 1 \mathrm{H})$, $3.44(\mathrm{~m}, 1 \mathrm{H}), 3.43(\mathrm{~m}, 1 \mathrm{H}), 3.38(\mathrm{~m}, 1 \mathrm{H}), 3.37(\mathrm{~m}, 1 \mathrm{H}), 3.25(\mathrm{~m}, 1 \mathrm{H}), 3.07(\mathrm{~m}, 1 \mathrm{H}), 2.79(\mathrm{~m}$, $1 \mathrm{H}), 2.48(\mathrm{dd}, \mathrm{J}=17.5 \mathrm{~Hz}, 7.5 \mathrm{~Hz}, 1 \mathrm{H}), 2.40(\mathrm{~m}, 1 \mathrm{H}), 2.74(\mathrm{~m}, 1 \mathrm{H}), 2.14(\mathrm{dd}, \mathrm{J}=13.5 \mathrm{~Hz}$, $7.0 \mathrm{~Hz} ; 1 \mathrm{H}), 2.08($ broad, $1 \mathrm{H}), 1.65(\mathrm{~m}, 2 \mathrm{H}), 1.63(\mathrm{~m}, 1 \mathrm{H}), 1.02(\mathrm{~d}, \mathrm{~J}=6.6 \mathrm{~Hz}, 1 \mathrm{H}) ;{ }^{13} \mathrm{C}-\mathrm{NMR}$ $\left(125 \mathrm{MHz}\right.$, acetone- $\left.\mathrm{d}_{6}\right) \delta=201.3,169.8,169.5,166.8,153.3,134.8,120.2,109.9,99.7,96.8,79.2$, $77.9,77.7,74.3,71.3,70.0,62.8,52.8,52.1,44.9,44.8,42.7,41.9,38.8,37.3,27.2,13.5$.

\subsection{HPLC-DAD-MS Analysis}

The HPLC-DAD-MS 1200 Series HPLC instrument (Agilent Technologies, Inc., Palo Alto, CA, USA) system equipped with an Agilent Poroshell 120 EC-C18 column $(2.7 \mu \mathrm{m}$ particles, $4.6 \times 100 \mathrm{~mm}$, Santa Clara, CA, USA) was used for the analysis of DE and its fractions. The gradient elution used $7 \mathrm{mM}$ ammonium acetate solution for solvents $\mathrm{A}$ and $\mathrm{ACN}$ with $0.1 \%$ formic acid for solvent B. The gradient for solvent A was $0 \mathrm{~min} 95 \%, 10 \mathrm{~min} 75 \%$, $18.5 \min 62.3 \%, 21 \mathrm{~min} 5 \%, 26 \min 5 \%, 26.01 \mathrm{~min} 95 \%, 31 \mathrm{~min} 95 \%$. The flow rate was 0.6 $\mathrm{mL} / \mathrm{min}$ and the injection volume was $5 \mu \mathrm{L}$. The DAD spectra were registered from 200 to $400 \mathrm{~nm}$. The parameters for MS analysis were set in the negative ion mode, with the spectra obtained in the $\mathrm{m} / \mathrm{z}$ range from 100 to 1000 . Nitrogen was used as the nebulizing and drying gas, and helium served as the collision gas. Peak identification was achieved by MS/MS analysis.

The quantification of the main substances was performed by HPLC-DAD according to the relative absorbance signal (in relation to the internal standard—bicalutamide, $40 \mathrm{mg} / \mathrm{L}$ ) at $254 \mathrm{~nm}$ according to the calibration curves of standards (chlorogenic acid, loganin, orientin, saponarin and isovitexin). Loganin was expressed as loganin, but the other iridoids (loganic acid, loganic acid ethyl ester, all bis-iridoid glycosides and silvestrosides 
III and IV) were calculated as loganin compounds. Chlorogenic acid and dichlorogenic acid isomers were expressed as chlorogenic acid compounds. Saponarin and luteolin derivates were calculated as saponarin compounds, isoorientin as an orientin compound and isovitexin directly from the relative standard curve.

\subsection{ORAC Assay}

The biological activity of DE and the prepared fractions was measured using the oxygen radical absorbance capacity (ORAC) with minor modifications as described by Naguib [33]. The fresh stock solutions were made each day and composed of $100 \mathrm{mM}$ phosphate buffer $(\mathrm{pH}=7.4), 10 \mathrm{nM}$ fluorescein in buffer, $300 \mu \mathrm{M}$ 6-hydroxy-2,5,7,8tetramethylchroman-2-carboxylic acid (Trolox) in buffer and $600 \mathrm{mM}$ 2,2'-azobis (2-amidinopropane) dihydrochloride (AAPH) in buffer.

The total volume of the reaction mixture was $3 \mathrm{~mL}$, the mixture was composed of $2.7 \mathrm{~mL}$ of $10 \mathrm{nM}$ fluorescein and $100 \mu \mathrm{L}$ sample/Trolox dilution, which was incubated at $37^{\circ} \mathrm{C}$ for $10 \mathrm{~min}$, and then $200 \mu \mathrm{L}$ of $40 \mathrm{mM}$ AAPH was added. The samples were measured by a Hitachi F-7000 Fluorescence Spectrophotometer (Chiyoda, Tokyo, Japan) at $\lambda_{\text {ex }} /$ em $495 / 520 \mathrm{~nm}$, slits $5 \mathrm{~nm}$, and the time scan was recorded for $1800 \mathrm{~s}$ once per s. The calibration for a well-known antioxidant, Trolox, was measured from 1 to $10 \mu \mathrm{M}$ and was given as area under curve change from $0 \mu \mathrm{M}$ Trolox (blank sample). All samples were measured in triplicate and the results given in mean Trolox equivalents per $100 \mathrm{~mL}$ of DE $(\mathrm{mM} \mathrm{TE} / 100 \mathrm{~mL}) \pm$ standard deviation (SD).

\subsection{Bacterial Strain, Media and Culture}

Low passage isolates $(\leq 8)$ of Borrelia burgdorferi strain B31 were obtained from the American Type Culture Collection (Manassas, VA, USA). Borrelia burgdorferi was cultured in BSK-H medium with $6 \%$ rabbit serum. All culture media were filter-sterilized using a $0.2 \mu \mathrm{m}$ filter. The cultures were incubated in $50 \mathrm{~mL}$ sterile closed conical tubes at $33^{\circ} \mathrm{C}$ in $5 \% \mathrm{CO}_{2}$ without antibiotics. After incubation for 7 days, the B. burgdorferi culture went into stationary phase $\left(\sim 10^{7}\right.$ spirochetes $\left./ \mathrm{mL}\right)[9,34]$, followed by the transferring of the bacterial cultures into 96-well tissue culture microplates for fraction screening.

\subsection{SYBR Green I/PI Assay}

To estimate the viability of B. burgdorferi, the SYBR Green I/propidium iodide (PI) assay was performed as described by Feng et al. [35]. Briefly, SYBR Green I $5 \mu \mathrm{L}(100 \times$ stock, Invitrogen, Waltham, MA, USA) and $5 \mu \mathrm{L}$ propidium iodide $(0.5 \mathrm{mM}$, Sigma, St. Louis, MO, USA) were added to each well and mixed thoroughly. The plates were incubated in the dark for $15 \mathrm{~min}$ at room temperature, with $\lambda_{\mathrm{ex}}$ at $450 \mathrm{~nm}$ and $\lambda_{\mathrm{em}}$ at $535 \mathrm{~nm}$ (green emission) and $635 \mathrm{~nm}$ (red emission) for each well of the screening plate using a TECAN Genios Pro microplate reader (Männedorf, Switzerland). Meanwhile, B. burgdorferi suspensions (live and $70 \%$ isopropyl alcohol killed) at five different proportions of live: dead cells $(0: 10,2: 8,5: 5,8: 2,10: 0)$ were mixed and added to the wells of the 96-well plate. Then, the SYBR Green I/PI reagent was added to each of the five samples, and the green/red fluorescence ratios for each proportion of live/dead B. burgdorferi were measured using the same parameters on the TECAN Genios Pro microplate reader as above. Using least-square fitting analysis, the regression equation and regression curve of the relationship between the percentage of live bacteria and the ratios of green/red fluorescence were obtained. The regression equation was used to calculate the percentage of live cells in each well of the screening plate.

\subsection{Evaluation of Bactericidal Effect of Test Compounds}

To evaluate the possible activity of DE and its fractions against stationary phase B. burgdorferi, the probes were added to $100 \mu \mathrm{L}$ of the seven-day old B. burgdorferi culture in the 96-well plate. The entire experiment was repeated in triplicate for each concentration of the tested compounds. All plates were incubated at $33{ }^{\circ} \mathrm{C}$ in $5 \% \mathrm{CO}_{2}$ for the next 7 days. 
Control cultures were treated with doxycycline, daptomycin and cefoperazone with a final concentration $50 \mu \mathrm{M}$. The live and dead cells were evaluated using the SYBR Green I/PI assay and the viability \% was calculated through the regression equation.

\subsection{Cell Culture}

The murine fibroblast NIH/3T3 cell line was obtained from the American Type Culture Collection. The cells were propagated in Dulbecco's modified Eagle's medium (DMEM) (Gibco, Waltham, MA, USA) supplemented with 10\% bovine calf serum (Gibco) and 5\% penicillin/streptomycin. The cells were incubated at $37{ }^{\circ} \mathrm{C}$ in a humidified $5 \% \mathrm{CO}_{2}$ and 95\% air atmosphere.

\subsection{Treatment Procedure and Sample Preparation}

The cells were plated at a density of $2.5 \times 10^{5}$ cells / well (The Countess ${ }^{\circledR}$ Automated Cell Counter, Invitrogen) in 96-well plates and incubated overnight. After $24 \mathrm{~h}$ of incubation, $100 \mu \mathrm{L}$ of fresh media or fresh media containing the 70\% EtOH ( $v / v \%)$ DE, NP2, NP5, NP7 and NP-RP (up to $5 \mu \mathrm{L}$ of each probe was added to $100 \mu \mathrm{L}$ fresh media) were added, and the cells were incubated for an additional $48 \mathrm{~h}$.

\subsection{Cell Viability Measured by WST-1}

The effect on the viability of cells was determined using the cell viability assay WST-1 (Roche Applied Science, Penzberg, Germany). WST-1 allows colorimetric measurement of cell viability due to reduction of tetrazolium salts to water-soluble formazan by viable cells. The amount of the formed formazan dye correlates with the number of viable cells. The measurements were completed $48 \mathrm{~h}$ after treatment of the cells. The experiments with addition of $5 \mu \mathrm{L}$ of $96 \%$ EtOH were used as a control. Five microliters per well of WST-1 reagent was added to $100 \mu \mathrm{L}$ cell culture medium, incubated at $37^{\circ} \mathrm{C}$ for $2 \mathrm{~h}$ and absorbance was measured at $450 \mathrm{~nm}$ using the TECAN Genios Pro microplate reader.

\subsection{Statistical Analysis}

Statistical analysis was performed by using one-way analysis of variance (ANOVA) with the post hoc Dunnett's multiple comparison test. All measurements represent data from at least three independent experiments, all performed in triplicate as mean \pm standard deviation (SD). The optical density of the control—cells treated only with solvent-was taken as $100 \%$ viability. Statistical significance of $p<0.05$ is represented as ${ }^{*}, p<0.001$ as ${ }^{* * *}$, $p<0.0001$ as $^{* * * *}$. Statistical analyses were performed with GraphPad Prism 7.

\section{Conclusions}

The ethanolic extract from Dipsacus fullonum L. leaves shows great potential as a possible source for novel lead compounds against stationary phase Borrelia burgdorferi. Although DE demonstrates the highest anti-Borrelia activity, the cytotoxicity of the raw extract clearly demonstrates the need for isolation of the most active and less cytotoxic fractions. The main compound classes from DE were polyphenols such as saponarin, isoorientin and isovitexin, and iridoids such as loganin, loganic acid and sylvestrosides III and IV. The highest cytotoxicity was found to originate from polyphenols, but was overcome by fractionation and purification to enhance the positive effects and reduce potential cytotoxic additives. The main active bis-iridoid compounds were fractionated, purified and identified as sylvestrosides III and IV by HPLC-DAD-MS/MS and verified by NMR. The bioactive sylvestrosides have great potential as noncytotoxic compounds for further testing against the latent forms of B. burgdorferi as separate phytochemicals or in combination with other bioactives, antibiotics and micronutrients.

Supplementary Materials: The following are available online at https:/ / www.mdpi.com/article/ 10.3390/ph15010087/s1, File S1: Statistical comparison of cytotoxic effect of DE and its fractions, File S2: Full NMR analysis. 


\begin{abstract}
Author Contributions: Conceptualization, M.V.; methodology, I.R. and O.B.; formal analysis, P.-R.L.; investigation, P.S.-R., O.B. and M.K. (Maria Kuhtinskaja); resources, M.K. (Maria Kulp); data curation, P.S.-R.; writing—original draft preparation, P.S.-R.; writing—review and editing, P.S.-R., O.B. and M.V.; visualization, P.S.-R.; supervision, M.V.; project administration, M.V.; funding acquisition, M.V. All authors have read and agreed to the published version of the manuscript.

Funding: This research was funded by the Archimedes Foundation (Development of additional analytical capabilities for Estonian Center of Analytical Chemistry, AKKI). Financial support from the Center of Excellence TK134 of the Archimedes Foundation and grant PSG11 of the Estonian Research council is acknowledged.
\end{abstract}

Institutional Review Board Statement: Not applicable.

Informed Consent Statement: Not applicable.

Data Availability Statement: Data is contained within the article or Supplementary Material.

Conflicts of Interest: The authors declare no conflict of interest.

\title{
References
}

1. Zimering, J.H.; Williams, M.R.; Eiras, M.E.; Fallon, B.A.; Logigian, E.L.; Dworkin, R.H. Acute and chronic pain associated with Lyme borreliosis: Clinical characteristics and pathophysiologic mechanisms. Pain 2014, 155, 1435-1438. [CrossRef] [PubMed]

2. Stanek, G.; Wormser, G.P.; Gray, J.; Strle, F. Lyme borreliosis. Lancet 2012, 379, 461-473. [CrossRef]

3. Di Domenico, E.G.; Cavallo, I.; Bordignon, V.; D’Agosto, G.; Pontone, M.; Trento, E.; Gallo, M.T.; Prignano, G.; Pimpinelli, F.; Toma, L.; et al. The emerging role of microbial biofilm in lyme neuroborreliosis. Front. Neurol. 2018, 9, 1048. [CrossRef] [PubMed]

4. Caskey, J.R.; Embers, M.E. Persister Development by Borrelia burgdorferi populations in vitro. Antimicrob. Agents Chemother. 2015, 59, 6288-6295. [CrossRef]

5. Sharma, B.; Brown, A.V.; Matluck, N.E.; Hu, L.T.; Lewis, K. Borrelia burgdorferi, the causative agent of lyme disease, forms drug-tolerant persister cells. Antimicrob. Agents Chemother. 2015, 59, 4616-4624. [CrossRef]

6. Stricker, R.B.; Sapi, E.; Kaur, N.; Anyanwu, S.; Luecke, D.F.; Datar, A.; Patel, S.; Rossi, M. Evaluation of in-vitro antibiotic susceptibility of different morphological forms of Borrelia burgdorferi. Infect. Drug Resist. 2011, 4, 97-113. [CrossRef]

7. Aucott, J.N.; Crowder, L.; Kortte, K.B. Development of a foundation for a case definition of post-treatment Lyme disease syndrome. Int. J. Infect. Dis. 2013, 17, e443-e449. [CrossRef]

8. Brorson, Ø.; Brorson, S.-H. Grapefruit seed extract is a powerful in vitro agent against motile and cystic forms of Borrelia burgdorferi sensu lato. Infection 2007, 35, 206-208. [CrossRef]

9. Theophilus, P.A.S.; Victoria, M.J.; Socarras, K.M.; Filush, K.R.; Gupta, K.; Luecke, D.F.; Sapi, E. Effectiveness of Stevia rebaudiana whole leaf extract against the various morphological forms of Borrelia burgdorferi in vitro. Eur. J. Microbiol. Immunol. 2015, 5, 268-280. [CrossRef]

10. Goc, A.; Niedzwiecki, A.; Rath, M. Cooperation of doxycycline with phytochemicals and micronutrients against active and persistent forms of Borrelia sp. Int. J. Biol. Sci. 2016, 12, 1093-1103. [CrossRef]

11. Goc, A.; Rath, M. The anti-borreliae efficacy of phytochemicals and micronutrients: An update. Ther. Adv. Infect. Dis. 2016, 3, 75-82. [CrossRef] [PubMed]

12. Zhao, Y.-M.; Shi, Y.-P. Phytochemicals and biological activities of dipsacus species. Chem. Biodivers. 2011, 8, 414-430. [CrossRef] [PubMed]

13. Chun, J.M.; Lee, A.Y.; Nam, J.Y.; Lim, K.S.; Choe, M.S.; Lee, M.Y.; Kim, C.; Kim, J.-S. Effects of dipsacus asperoides extract on monosodium iodoacetate-Induced osteoarthritis in rats based on gene expression profiling. Front. Pharmacol. 2021, 12, 293. [CrossRef] [PubMed]

14. Rauwald, H.W.; Liebold, T.; Straubinger, R.K. Growth inhibiting activity of lipophilic extracts from Dipsacus sylvestris Huds. roots against Borrelia burgdorferi s. s. in vitro. Die Pharm. Int. J. Pharm. Sci. 2011, 66, 628-630. [CrossRef]

15. Feng, J.; Leone, J.; Schweig, S.; Zhang, Y. Evaluation of natural and botanical medicines for activity against growing and non-growing forms of B. burgdorferi. Front. Med. 2020, 7, 6. [CrossRef] [PubMed]

16. Oszmiański, J.; Wojdyło, A.; Juszczyk, P.; Nowicka, P. Roots and leaf extracts of Dipsacus fullonum L. and Their biological activities. Plants 2020, 9, 78. [CrossRef]

17. Yang, B.; Feng, X.; Xu, J.; Lei, H.; Zhang, L. Multi-component HPLC analysis and antioxidant activity characterization of extracts from Dipsacus sativus (Linn.) Honck. Int. J. Food Prop. 2016, 19, 1000-1006. [CrossRef]

18. Kuhtinskaja, M.; Bragina, O.; Kulp, M.; Vaher, M. Anticancer Effect of the Iridoid Glycoside Fraction from Dipsacus fullonum L. Leaves. Nat. Prod. Commun. 2020, 15. [CrossRef]

19. Vaher, M.; Kuhtinskaja, M. Extraction and analysis of bioactive compounds from dipsacus fullonum and galium verum for lyme borreliosis treatment. Biomed. J. Sci. Tech. Res. 2018, 11, 8614-8616. [CrossRef]

20. Sherma, J.; Fried, B. Handbook of Thin-Layer Chromatography, 3rd ed.; Marcel Dekker, Inc.: Basel, Switzerland, 2003 ; Volume 89. 
21. Ji, D.; Zhang, C.; Li, J.; Yang, H.; Shen, J.; Yang, Z. A new iridoid glycoside from the roots of dipsacus asper. Molecules 2012, 17, 1419-1424. [CrossRef]

22. Zhang, H.; Rothwangl, K.; Mesecar, A.D.; Sabahi, A.; Rong, L.; Fong, H.H.S. Lamiridosins, hepatitis C virus entry inhibitors from lamium album. J. Nat. Prod. 2009, 72, 2158-2162. [CrossRef]

23. Matsuo, M.; Sasaki, N.; Saga, K.; Kaneko, T. Cytotoxicity of flavonoids toward cultured normal human cells. Biol. Pharm. Bull. 2005, 28, 253-259. [CrossRef]

24. Min, S.-Y.; Park, C.-H.; Yu, H.-W.; Park, Y.-J. Anti-inflammatory and anti-allergic effects of saponarin and its impact on signaling pathways of RAW 264.7, RBL-2H3, and HaCaT Cells. Int. J. Mol. Sci. 2021, 22, 8431. [CrossRef]

25. Jiang, Y.; Kusama, K.; Satoh, K.; Takayama, F.; Watanabe, S.; Sakagami, H. Induction of cytotoxicity by chlorogenic acid in human oral tumor cell lines. Phytomedicine 2000, 7, 483-491. [CrossRef]

26. Feng, J.; Auwaerter, P.G.; Zhang, Y. Drug combinations against Borrelia burgdorferi Persisters in vitro: Eradication achieved by using daptomycin, cefoperazone and doxycycline. PLoS ONE 2015, 10, e0117207. [CrossRef]

27. Briguglio, G.; Costa, C.; Pollicino, M.; Giambò, F.; Catania, S.; Fenga, C. Polyphenols in cancer prevention: New insights (Review). Int. J. Funct. Nutr. 2020, 1, 9. [CrossRef]

28. Fujimoto, A.; Sakanashi, Y.; Matsui, H.; Oyama, T.; Nishimura, Y.; Masuda, T.; Oyama, Y. Cytometric analysis of cytotoxicity of polyphenols and related phenolics to rat thymocytes: Potent cytotoxicity of resveratrol to normal cells. Basic Clin. Pharmacol. Toxicol. 2009, 104, 455-462. [CrossRef]

29. Kocsis, Á.; Szabó, L.F.; Podányi, B. New bis-iridoids from dipsacus laciniatus. J. Nat. Prod. 1993, 56, 1486-1499. [CrossRef]

30. Jensen, S.R.; Lyse-Petersen, S.E.; Nielsen, B.J. Novel bis-iridoid glucosides from Dipsacus sylvestris. Phytochemistry 1979, 18, 273-277. [CrossRef]

31. Chen, Y.; Yu, H.; Guo, F.; Wu, Y.; Li, Y. Antinociceptive and anti-inflammatory activities of a standardizedextract of bis-iridoids from Pterocephalus hookeri. J. Ethnopharmacol. 2018, 216, 233-238. [CrossRef]

32. Rahman, A.U.; Ahmad, V.U. ${ }^{13}$ C-NMR of Natural Products; Springer: Boston, MA, USA, 1992; Volume 1. [CrossRef]

33. Naguib, Y.M. A Fluorometric Method for Measurement of Oxygen Radical-Scavenging Activity of Water-Soluble Antioxidants. Anal. Biochem. 2000, 284, 93-98. [CrossRef]

34. Feng, J.; Wang, T.; Shi, W.; Zhang, S.; Sullivan, D.; Auwaerter, P.G.; Zhang, Y. Identification of novel activity against Borrelia burgdorferi persisters using an FDA approved drug library. Emerg. Microbes Infect. 2014, 3, 1-8. [CrossRef]

35. Feng, J.; Wang, T.; Zhang, S.; Shi, W.; Zhang, Y. An optimized SYBR green I/PI assay for rapid viability assessment and antibiotic susceptibility testing for Borrelia burgdorferi. PLoS ONE 2014, 9, e111809. [CrossRef] 